\title{
Evaluation of Externality Costs in Life-Cycle Optimization of Municipal Solid Waste Management Systems
}

Martinez Sanchez, Veronica; Levis, James W.; Damgaard, Anders; DeCarolis, Joseph F.; Barlaz, Morton A.; Astrup, Thomas Fruergaard

\section{Published in:}

Environmental Science and Technology

Link to article, DOI:

10.1021/acs.est.6b06125

Publication date:

2017

Document Version

Peer reviewed version

Link back to DTU Orbit

Citation (APA):

Martinez Sanchez, V., Levis, J. W., Damgaard, A., DeCarolis, J. F., Barlaz, M. A., \& Astrup, T. F. (2017).

Evaluation of Externality Costs in Life-Cycle Optimization of Municipal Solid Waste Management Systems.

Environmental Science and Technology, 51(6), 3119-3127. https://doi.org/10.1021/acs.est.6b06125

\section{General rights}

Copyright and moral rights for the publications made accessible in the public portal are retained by the authors and/or other copyright owners and it is a condition of accessing publications that users recognise and abide by the legal requirements associated with these rights.

- Users may download and print one copy of any publication from the public portal for the purpose of private study or research.

- You may not further distribute the material or use it for any profit-making activity or commercial gain

- You may freely distribute the URL identifying the publication in the public portal 


\title{
Evaluation of Externality Costs in Life-Cycle Optimization of Municipal Solid Waste Management Systems
}

\author{
Veronica Martinez-Sanchez ${ }^{* 1,2}$, James W. Levis ${ }^{3}$, Anders Damgaard ${ }^{2}$, Joseph F. \\ DeCarolis $^{3}$, Morton A. Barlaz ${ }^{3} \&$ Thomas F. Astrup ${ }^{2}$
}

${ }^{1}$ Fundació ENT, Carrer Sant Joan 39, 08800 Vilanova i la Geltrú (Barcelona), Spain

${ }^{2}$ Department of Environmental Engineering, Technical University of Denmark, Building 115, DK2800 Kgs. Lyngby, Denmark

${ }^{3}$ Department of Civil, Construction, and Environmental Engineering, North Carolina State University. Campus Box 7908, Raleigh, North Carolina 27695-7908, United States

*Corresponding author. Address: Carrer Sant Joan 39, 08800 Vilanova i la Geltrú (Barcelona), Spain; Telephone: (+0034) 938935 104; E-mail: vmartinezs@ent.cat

"NOTE: this is the author's version of a work that was accepted for publication in Environmental Science \&Technology. Changes resulting from the publishing process, such as peer review, editing, corrections, structural formatting, and other quality control mechanisms may not be reflected in this document. Minor changes may have been made to this manuscript since it was accepted for publication. A definitive version is published in Environmental Science \&Technology, vol 51(6), 2017 , doi: http:// 10.1021/acs.est.6b06125” 


\begin{abstract}
The development of sustainable solid waste management (SWM) systems requires consideration of both economic and environmental impacts. Societal life-cycle costing (S-LCC) provides a quantitative framework to estimate both economic and environmental impacts, by including "budget costs” and "externality costs.” Budget costs include market goods and services (economic impact), while externality costs include effects outside the economic system (e.g. environmental impact). This study demonstrates the applicability of S-LCC to SWM life-cycle optimization through a case study based on an average suburban U.S. county of 500,000 people generating 320,000 Mg of waste annually. Estimated externality costs are based on emissions of $\mathrm{CO}_{2}, \mathrm{CH}_{4}, \mathrm{~N}_{2} \mathrm{O}, \mathrm{PM}_{2.5}, \mathrm{PM}_{10}, \mathrm{NO}_{\mathrm{X}}, \mathrm{SO}_{2}, \mathrm{VOC}, \mathrm{CO}, \mathrm{NH}_{3}, \mathrm{CO}, \mathrm{Hg}, \mathrm{Pb}, \mathrm{Cd}, \mathrm{Cr}(\mathrm{VI}), \mathrm{Ni}, \mathrm{As}$, and dioxins. The results indicate that incorporating S-LCC into optimized SWM strategy development encourages the use of a mixed waste material recovery facility with residues going to incineration, and separated organics to anaerobic digestion. Results are sensitive to waste composition, energy mix and recycling rates. Most of the externality costs stem from $\mathrm{SO}_{2}, \mathrm{NO}_{\mathrm{x}}, \mathrm{PM}_{2.5}, \mathrm{CH}_{4}$, fossil $\mathrm{CO}_{2}$, and $\mathrm{NH}_{3}$ emissions. S-LCC proved to be a valuable tool for policy analysis, but additional data on key externality costs such as organic compounds emissions to water would improve future analyses.
\end{abstract}

Key words: welfare economy, waste management, optimization, life-cycle approach, externality costs, budget cost, social costs 


\section{INTRODUCTION}

Assessing the economic and environmental implications of solid waste management (SWM) strategies is an essential component of sustainable civil infrastructure. This assessment requires estimating the economic and environmental impacts of collecting, separating, treating, and disposing of waste, as well as estimating savings obtained through recovery of resources and energy. Identifying optimal SWM strategies, however, is a complex undertaking.

The systematic analysis and comparison of the environmental and economic performance of SWM strategies have been evaluated through different decision-support frameworks, including life-cycle assessment (LCA) and life-cycle costing (LCC) (e.g., Martinez-Sanchez et al. ${ }^{1}$ and Bernstad \& Andersson ${ }^{2}$ ). However, most of these studies use "what-if” approaches to define SWM scenarios in simulation models, with technology pathways defined a priori. This type of assessment identifies the preferred solution within a selection of proposed technology scenarios, but does not provide information on the performance of other potential combinations of technologies or management strategies. To overcome this limitation, Levis et al. ${ }^{3-5}$ developed an optimization model (SWOLF - Solid Waste Optimization Life-cycle Framework) to identify SWM strategies that meet specific objectives (e.g., minimal costs or minimal greenhouse gas [GHG] emissions), while complying with a set of constraints (e.g., mass balance, policy targets, plant capacities). While a few optimization models have been developed to address specific aspects of waste management systems (e.g., Wang et al., ${ }^{6}$ Soderman et al., ${ }^{7}$ and Costi et al. ${ }^{8}$ ), SWOLF $^{3,4}$ is the only optimization tool with a life-cycle framework covering SWM from waste generation through collection, treatment, and final disposal or recovery that is able to optimize different variables, such as budget cost and GHG emissions.

Although life-cycle optimization models can be used to evaluate trade-offs between economic cost and specific emissions or impacts over the life-cycle of a product or service, they have typically considered only a small set of emissions and have not attempted to comprehensively consider the full damage from a wide range of environmental emissions. Incorporating societal lifecycle costing (S-LCC) into the life-cycle optimization framework addresses this challenge by implementing a single indicator that integrates economic, environmental and social impacts (i.e. social costs measured in monetary terms). ${ }^{1}$ S-LCC is a welfare economic assessment (socioeconomic assessment) that estimates the welfare losses and gains of a system by including "budget costs” and “externality costs.” Budget costs account for marketed goods and services (e.g., labor 
and capital equipment costs), i.e. financial costs excluding taxes and other transfers, while externality costs represent the monetized effects occurring outside of the economic system, such as environmental emissions, i.e. welfare costs of non-market goods. ${ }^{1}$ To date, externality costs have been used in different areas, for example within policy development for estimating optimal gasoline taxes in the U.S. ${ }^{9}$ or potential subsidies for promoting sustainable agriculture in the UK, ${ }^{10}$ but externality costs have never been used in a SWM life-cycle optimization framework, although these costs could potentially have profound influence on the selection of SWM strategies.

The objective of this study was to demonstrate how social costs can be integrated into a decision support tool for waste management and to describe the implications of using S-LCC instead of other indicators such as budget costs, externality costs or GHG emissions. A life-cycle optimization model (SWOLF) was for the first time extended to include social costs and used for a case study. The study demonstrates the applicability of the method and identifies critical pollutants for which externality costs should be established in future studies.

\section{MODELING APPROACH}

\section{Case study definition}

The functional unit was the annual waste generated by a suburban U.S. county of 500,000 people with a reference flow of 320,000 Mg of waste per year $(1 \mathrm{Mg}=1,000 \mathrm{~kg})$ based on the U.S. average waste generation for 2015 reported by Levis et al. ${ }^{3}$ This population provides the necessary scale to consider options such as waste-to-energy (WtE) combustion. The case study does not represent any specific site/region, but a generic scenario with average emissions to demonstrate the applicability of the method. The system boundaries of the study included waste generation through final disposal as well as land application of the treated waste (e.g., compost products), conversion of recyclables to new materials (material remanufacturing), and recovered energy. Figure 1 shows the waste processes included in this study and details of each facility/process can be found in the Supporting Information (SI). Every combination of the illustrated processes was considered by the optimization framework. While SWOLF includes additional processes beyond those presented in the figure, the system was simplified to illustrate the consideration of externality costs in a lifecycle optimization model. 


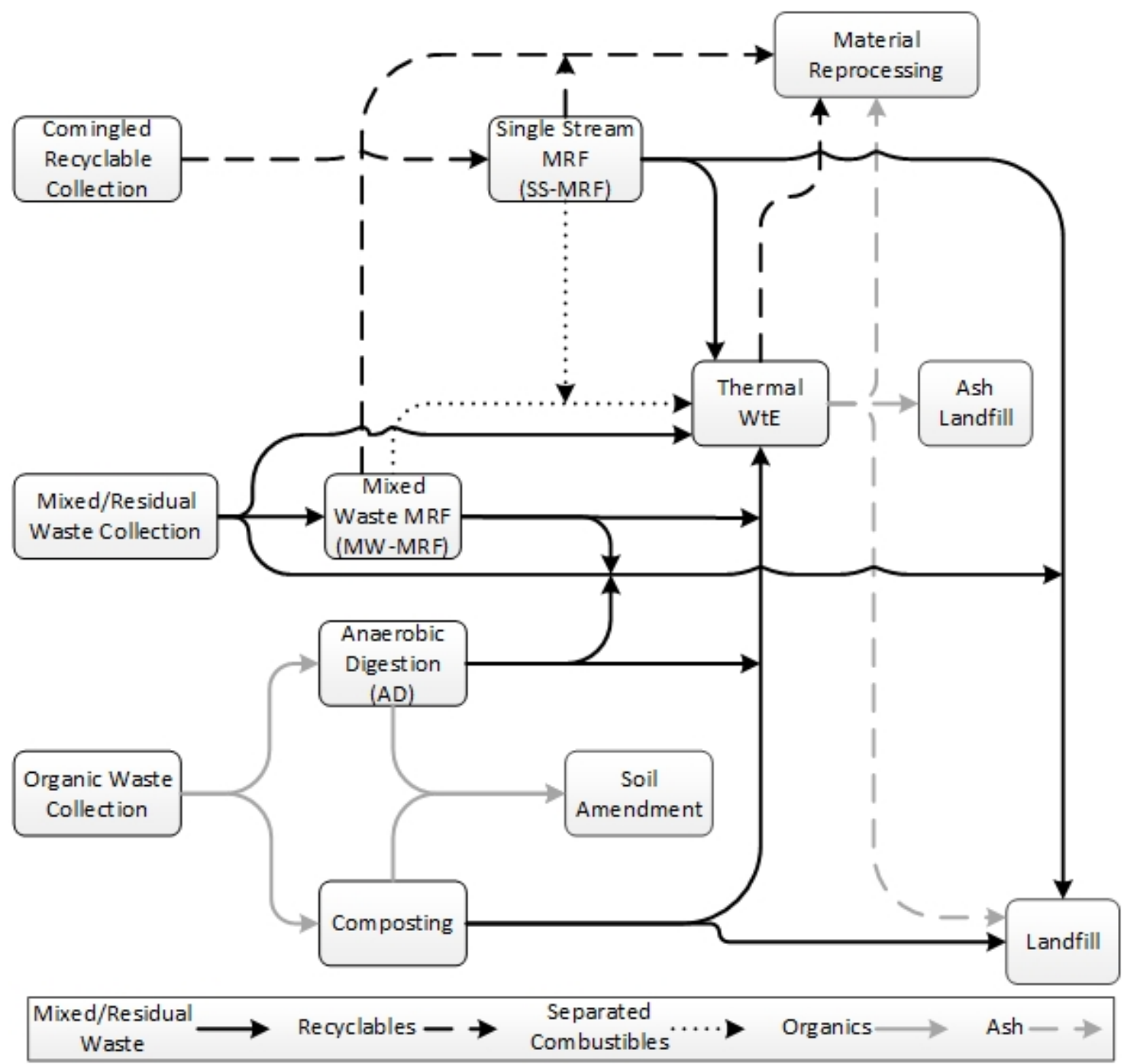

Figure 1 SWOLF processes included in the study. WtE: Waste-to-Energy, MRF: Material Recovery Facility. The distinction between bottom and fly ash is not shown for simplicity. Mixed waste represents waste collected from households, either with or without concurrent collection of source-separated fractions. The "Mixed/Residual Waste" flows from both MRFs to Thermal WtE represent unseparated remaining materials. The "Separated Combustibles" from both MRFs to Thermal WtE represented separated materials, such as separated paper or plastic streams. The biogas generated in the anaerobic digestion is used for electricity production. Digestate and compost are assumed to substitute peat. Residues generated from MRFs, Anaerobic Digestion and Composting can be either incinerated or landfilled. Details of the modeled facilities can be found in SI-2.

This study used a single-stage optimization for 2015 with no existing facilities. This "greenfield" analysis was meant to identify the societal optimum strategy without the constraints of an existing system. In an actual decision context, the existing system could be included in the optimization as it could impact both the LCA and S-LCC. This means that the LCA is carried out as an attributional LCA (Situation A, ILCD 2010) with use of average processes in the background system. 
The study adopted the same data and process models as used in Levis et al., ${ }^{3}$ covering: 30 waste materials, nine waste processes (separation, collection, treatment, and disposal), the 2015 waste composition from Levis et al. ${ }^{4}$ (Table S2) and the electricity mix from U.S. National mix estimated from eGRID ${ }^{11}$ for 2015 (Table S9). Key parameters and assumptions for the study are provided in Section 2 of the SI. The importance of waste composition and electricity generation fuel mix composition was assessed through scenario analysis with two alternative waste compositions, one with more organics and less paper (predicted waste composition for 2035 in Levis et al. ${ }^{3}$ ) and the other with less organics and more recyclables (waste composition for 2000 in ${ }^{12}$ ), and two extreme electricity mixes (100\% coal and 100\% wind), as summarized in Tables S2 and S7. The objective of the sensitivity analyses was to evaluate the robustness of the societal optimum under different waste compositions and GHG-intensities of offset electricity.

\section{Optimization Modeling}

SWOLF is a deterministic, optimizable life-cycle framework that finds the solid waste strategy (e.g., mass flows and technology choices) that meets a specific objective function while also meeting user-defined constraints for a user-defined integrated SWM system. ${ }^{3}$ SWOLF includes a detailed set of life-cycle process models (e.g., collection, remanufacturing, landfill including long-term emissions), a mathematical programming-based multistage system model that embeds waste mass flow equations, and a linear programming model solver (e.g., CPLEX ${ }^{13}$ or $\mathrm{GLPK}^{14}$ ), as described in Levis et al. ${ }^{4}$

S-LCC is a welfare economic assessment method that includes budget costs and externality costs, both measured in accounting prices. Accounting prices are indicators of the marginal utility (welfare) provided by goods and services. ${ }^{1,15}$ Accounting prices for market goods/services (e.g., fuel) were assumed equal to their market prices excluding transfers (i.e., taxes, subsidies, and fees). The accounting price of an externality represents the marginal damage of the externality (e.g., emission) in society and includes both market and non-market costs (e.g., medical treatment of illnesses or injuries caused by emissions and willingness-to-pay to avoid these damages). Some studies used marginal abatement cost of the externality (e.g., costs associated with more advanced air pollution control for a specific emission) as a proxy for the marginal damage cost, when the latter is not available. ${ }^{16}$ The social cost (SC) of a SWM strategy (final output of an S-LCC analysis) represents the sum of its budget cost $(B C)$ and externality costs $(E C)$. 
To use SWOLF with S-LCC functionality, the accounting prices of selected pollutants (Section 2.3) were added to the existing budget costs (referred to as “engineering costs" in Levis et al. ${ }^{4}$ ) that included amortized capital costs and operating costs.. The EC of each emission $j$ associated with each process $i$ was defined per Mg of waste throughput as a product of the amount of emission per $\mathrm{Mg}$ of waste throughput $\left(e_{i, j}\right)$ and the accounting price for the emission $\left(A P_{j}\right)$. The product was multiplied by the waste throughput of the specific process model $\left(m_{i}\right)$, as shown in Equation 1.

$$
E C=\sum_{i} m_{i} \cdot \sum_{j} e_{i, j} \cdot A P_{j}
$$

A standard constraint method (i.e. one variable is optimized while another variable is constrained at different levels) was used to develop trade-off curves for budget costs, externality costs, and GHG emissions in which externality costs or GHG emissions of the SWM strategy were minimized while budget costs were constrained. The results included the waste flows to each waste process and the sizes of the facilities as well as budget costs, externality costs, and GHG emissions for each strategy.

\section{Accounting Price Modeling}

The choice of pollutants included in the externality costs was motivated by previous investigations in the field of waste management (Eshet et al., ${ }^{17-19}$ Rabl et al.,, ${ }^{20,21}$ Dijkgraaf et al. ${ }^{22}$ and EU Commision ${ }^{23}$ ). The assessment excludes water and soil pollution, resource consumption as well as social impacts (such as time used by households, odor, noise, visual instruction, congestion, and other disamenities) due to the lack of representative data. It should be noted that this is not a method limitation but a data constraint, i.e. S-LCC can include all of these externalities if their accounting prices are available.

Best estimates of the accounting price for individual pollutants were based on available literature. Studies were selected based on the case study's location, transparency of the estimates, and adaptability to this study. The first priority was given to studies in the U.S., but when U.S. data were not available, EU data were adopted. For example, most of the U.S. studies estimated accounting prices for emissions from different industries (e.g., agriculture or energy) and included key air pollutants, such as $\mathrm{PM}_{2.5}, \mathrm{NO}_{\mathrm{X}}, \mathrm{SO}_{2}$, VOC, and $\mathrm{NH}_{3}$ (e.g., ${ }^{24-29}$ ), but excluded toxic compounds (e.g., Hg, Pb, Cd, and dioxins). To include toxic compounds, European data sources such as ExternE ${ }^{30}$ were applied. In addition, studies reporting externality costs without the 
associated emission were not used, because the accounting price calculation was not possible. For example, Grosse ${ }^{31}$ estimated the economic benefit of reducing $\mathrm{Pb}$ in the U.S. to be $\$ 110-\$ 319$ billion per annum, but did not relate these costs to the amount of emissions reduction. Table S1 shows the accounting price of each pollutant used in this study together with the reported ranges. The accounting prices of the included pollutants are discussed in the following sections.

\section{Greenhouse Gas Emissions}

For $\mathrm{CO}_{2}$, we applied the accounting price reported by the U.S. EPA for $2015{ }^{32}$ which was calculated with a $3 \%$ discount rate, in the baseline results $\left(\$ 0.039 \mathrm{~kg}^{-1} \mathrm{CO}_{2}\right)$. This is 10 times greater than the value reported by $\mathrm{Tol}^{33}$. Other studies using marginal abatement costs as a proxy (e.g., RDC Environment ${ }^{34}$ ) and/or applying benefit transfer techniques (e.g., Roth ${ }^{28}$ and $\mathrm{Tol}^{33}$ ) were included in the ranges reported in Table S1, but were not used in the model. The accounting prices for $\mathrm{CH}_{4}\left(\$ 0.819 \mathrm{~kg}^{-1} \mathrm{CH}_{4}\right)$ and $\mathrm{N}_{2} \mathrm{O}\left(\$ 11.62 \mathrm{~kg}^{-1} \mathrm{~N}_{2} \mathrm{O}\right)$ were calculated using their 100 year global warming potential from the IPCC $(2007)^{35}$ (25 and $298 \mathrm{~kg} \mathrm{CO}_{2 \mathrm{eq}} \mathrm{kg}^{-1}$, respectively) and the accounting price for $\mathrm{CO}_{2}$, as done in other studies. ${ }^{20,34,36}$ Biogenic $\mathrm{CO}_{2}$ emissions were considered neutral (since release and sequestration balance each other over a relatively short time frame), while long-term biogenic carbon storage was accounted for with the negative of the value of fossil carbon, as commonly done by the LCA community and in some economic studies (e.g., Roth, ${ }^{28}$ Eunomia $^{36}$ ). However, the ExternE project and associated studies (e.g., Rabl et al. ${ }^{20,37}$ ) treat all $\mathrm{CO}_{2}$ emissions equally, regardless of their origin. To assess the importance of this assumption, a sensitivity analysis was done by considering the same accounting price for biogenic and fossil $\mathrm{CO}_{2}$ as well as for long-term biogenic carbon storage.

\section{General Air Pollutants}

Three studies reporting U.S. data were used to estimate the accounting prices for $\mathrm{PM}_{2.5}$ (\$342 kg-1 $\left.\mathrm{PM}_{2.5}\right), \mathrm{NO}_{\mathrm{x}}\left(\$ 40 \mathrm{~kg}^{-1} \mathrm{NO}_{\mathrm{x}}\right), \mathrm{SO}_{2}\left(\$ 64 \mathrm{~kg}^{-1} \mathrm{SO}_{2}\right), \mathrm{VOC}\left(\$ 1.5 \mathrm{~kg}^{-1} \mathrm{VOC}\right)$, and $\mathrm{NH}_{3}(\$ 26$ $\left.\mathrm{kg}^{-1} \mathrm{NH}_{3}\right) .{ }^{38-40}$ The range of estimates shown in Table $\mathrm{S} 1$ may be due to different approaches for linking emissions to air quality, as well as the choice of emission source. In the estimates by Muller et al. ${ }^{38,41,42}$ and Fann et al. ${ }^{40,43}$, the health effects of particulate precursors $\left(\mathrm{NO}_{\mathrm{x}}, \mathrm{SO}_{2}, \mathrm{VOC}\right.$, and $\mathrm{NH}_{3}$ ) were assumed to arise indirectly from their particulate nature and were calculated by applying the $\mathrm{PM}_{2,5}$ accounting price to their aerosol concentration, as done for $\mathrm{NO}_{\mathrm{x}}$ and $\mathrm{SO}_{2}$ in the ExternE project. ${ }^{20}$ The accounting prices for CO $\left(\$ 0.9 \mathrm{~kg}^{-1} \mathrm{CO}\right)$ and $\mathrm{PM}_{10}\left(\$ 3 \mathrm{~kg}^{-1} \mathrm{PM}_{10}\right)$ were calculated as medians of the estimates made by Matthews \& Lave, ${ }^{44}$ Roth $^{28}$ and Muller et al. ${ }^{38}$ The 
accounting price of particulate matter includes not only the damage caused by its physical effects, but also the damage caused by compounds adsorbed to particulate matter.

\section{Toxic air emissions}

For Hg emissions, we used the median of Rice and Hammit ${ }^{45}$ in the baseline $\left(\$ 87,000 \mathrm{~kg}^{-1}\right.$ $\mathrm{Hg}$ ) because this value included cognitive and cardiovascular health effects, while Trasande et al. ${ }^{46}$ only included cognitive effects. Both studies ${ }^{45,46}$ focused only on damage within the U.S., which may underestimate the true costs, as Hg impacts are global due to the long residence time in the atmosphere that results in near uniform mixing. ${ }^{47} \mathrm{~Pb}$ exposure causes many adverse health effects, one of which commonly observed in the U.S. is the impairment of neurodevelopment among children. ${ }^{31}$ This damage can be measured as reduced cognitive performance in standardized IQ (Intelligence Quotient) tests of general intellectual ability. Several studies have focused on $\mathrm{Pb}$ in the U.S., but none have related externality cost to an amount of emission (e.g., Grosse ${ }^{31}$ ). Therefore we combined data on Pb-related IQ reductions from two EU studies ${ }^{20,48}$ (e.g., $0.0032 \mathrm{IQ} \mathrm{kg}^{-1} \mathrm{~Pb}$ Pizzol average for the years 2000-2002, using base case estimations) with U.S. estimates of the cost of IQ reductions reported by Grosse ${ }^{31}$ (\$14,500 IQ point $\left.{ }^{-1}\right)$. The key assumption for this conversion is that emitting a given mass of $\mathrm{Pb}$ causes the same neurological damage in the $\mathrm{EU}$ and in the U.S. No specific data were found for other toxic metals and organic compounds for the U.S. Thus, EU values from Rabl et al. ${ }^{20}$ were recalculated for the U.S. using $\$ 5.9 \mathrm{M}$ for the value of a statistical life, as used in Rice \& Hammit, ${ }^{45}$ instead of 2 M€ per premature cancer death in Rabl et al. $^{20}$ The resulting accounting prices are $\$ 115 \mathrm{~kg}^{-1} \mathrm{Cd}, \$ 590 \mathrm{~kg}^{-1} \mathrm{Cr}(\mathrm{VI}), \$ 11 \mathrm{~kg}^{-1} \mathrm{Ni}, \$ 236 \mathrm{~kg}^{-1} \mathrm{As}$, and $\$ 550,000,000 \mathrm{~kg}^{-1}$ Dioxin.

The damage caused by the particulate form of these toxic emissions is accounted in both the accounting price of the particulate matter (where a minor fraction is attributable to heavy metals), as well as in their emissions accounting price. Such double-counting cannot be avoided due to the aggregated nature of the estimates for accounting prices, but it can be assumed minor since only a small part of the toxic emissions are absorbed by particulates while most of are in vapor form (e.g. particulate $\mathrm{Hg}$ accounts for less than $10 \%$ of the atmospheric mercury ${ }^{49}$ ).

\section{RESULTS AND DISCUSSION}

Figure 2 shows the optimization results using the baseline assumptions. The extremes of the curves shown in Figure 2A represent the cases when minimizing either externality costs "min EC" 
or budget costs "min BC". The cases in between these extremes were obtained by minimizing externality costs while imposing different budget constraints. The name given to these cases comprised a letter from A to $\mathrm{K}$, representing the magnitude of the budget constraint, and the objective function used in parenthesis - (EC) minimizing externality costs. The case “A (EC)” had a budget constraint of $\$ 52.5 \mathrm{M}$ per functional unit $(320,000 \mathrm{Mg})$ and there was a budget increase of $\$ 1.8 \mathrm{M}$ per functional unit in between consecutive letters (e.g., the case “B (EC)” had a budget constraint of $\$ 54.3 \mathrm{M}$ per functional unit). The detailed results of each case, together with the budget constraint and objective function, are summarized in Table S10. In the description below, cases are grouped when using similar treatments and named "sets of cases.”

Moving from the minimal budget cost case "min BC" to the minimal externality cost case “min EC”, there was a first set of cases in which mixed waste was routed either to landfill or mixed waste Material Recovery Facility (MW-MRF), as shown in Figure 2C. For these cases, from "min $\mathrm{BC}$ ” to "E (EC)," the organic residues from the MW-MRF were sent to anaerobic digestion, and except for “A (EC)”, non-organic MW-MRF residues were sent to WtE (Table S10). The budget constraint in case “A (EC)” did not allow building a WtE for the non-organic MW-MRF residues and instead these residues were sent to landfill. As more waste was sent to a MW-MRF over landfilling, within this set of cases, lower externality costs and larger budget costs resulted.

The externality cost of collecting all waste and landfilling, represented by the case "min BC” (\$55 per Mg), was larger than the values reported by Rabl et al., ${ }^{20}$ Dijkgraaf et al., ${ }^{22}$ and the European Commission $^{50}$, which were 12, 25, and 7-27 \$ per Mg, respectively. This difference may be related to several factors, such as different system boundaries (our modeling includes 100-yr landfill emissions and collection, while the others do not; collection causes half of the cases' externality costs), as well as different direct emission inventories, waste composition, electricity offsets and accounting prices for the emissions (e.g., the $\mathrm{CO}_{2}$ accounting price in the previous studies was half of the value used in this investigation).

From case "E (EC)” to “J (EC)” there was a second set of cases in which waste is distributed between WtE, a single-stream MRF (SS-MRF) and MW-MRF. Greater use of WtE and SS-MRF instead of MW-MRF led to lower externality costs and larger budget costs. The last set of cases was represented by cases "K (EC)” and “min EC” in which waste was routed either to WtE or SS-MRF. In the "min EC" case, $12 \%$ of the waste was sent to SS-MRF and the rest to WtE. The streams sent to the SS-MRF included: metals (ferrous and non-ferrous), PET, paper containers, 
paper bags, third-class mail, and newsprint, all of which were recovered at their maximum participation rates (Table S3). Other fractions, such as glass, plastic (except PET) and fiber (such magazines, office paper, and corrugated cardboard), remained with the residual waste because the net externality cost of waste-to-energy combustion was less than the externality costs of the energy consumed to recycle these materials. The budget constraint of case "K (EC)” limited the capacity of the SS-MRF to $11 \%$ of the waste instead of the $12 \%$ used in the "min EC" solution. However, both cases result in nearly the same budget and externality costs.

The overall technological shift from landfilling (represented by “min BC”) towards WtE and SS-MRF (represented by “min EC”) was associated with increasing recycling and energy generation, which avoided externality costs related to $\mathrm{SO}_{2}$, fossil $\mathrm{CO}_{2}$, and other emissions from energy production, as well as lower direct $\mathrm{CH}_{4}, \mathrm{NO}_{\mathrm{x}}$, and $\mathrm{PM}_{2.5}$ emissions. These savings were larger than the cost of reduced carbon storage in the landfill. Table S11 shows the contribution of each emission to the externality costs of these two extreme cases, “min BC" and "min EC". Most of the externality costs were caused by $\mathrm{SO}_{2}, \mathrm{NO}_{\mathrm{X}}, \mathrm{PM}_{2.5}, \mathrm{CH}_{4}$, fossil $\mathrm{CO}_{2}$ and $\mathrm{NH}_{3}$ (Table S11), while the remaining emissions with published accounting prices had minor impacts.

The societal optimal solution of the case study, i.e., the case with the minimal social cost (sum of externality costs and budget costs), is case “E (EC),” whose social cost was \$67 per Mg (Figure 2B). In this case, all the waste is routed to MW-MRF with residues going to incineration and separated organics to anaerobic digestion. The case "min EC" had the largest externality benefits, but also the highest budget costs and a social cost of $\$ 87$ per $\mathrm{Mg}$, which is $30 \%$ larger than the societal optimal solution. Conversely, the solution "min BC" had the lowest budget costs but very high externality costs that led to the overall highest social cost (\$217 per $\mathrm{Mg}$ ).

Figure 3 shows social cost versus GHG emissions per Mg of waste input for each case. When moving from the "min BC" case to the societal optimal solution, case "E (EC)”, in which all the waste is sent to MW-MRF, there is a GHG reduction of $125 \mathrm{~kg} \mathrm{CO}_{2}$ per $\mathrm{Mg}$ as well as a social cost decrease (-\$150 per Mg). The introduction of WtE and SS-MRF, solution “F (EC)", further increased GHG savings (-2 kg CO 2 per $\mathrm{Mg}$ ), but an additional increase in WtE from " $\mathrm{F}$ (EC)” to “G (EC)” decreased the GHG benefits, due to an increase in plastic combustion leading to higher fossil $\mathrm{CO}_{2}$ emissions. From “G (EC)” to “J (EC)”, social cost increases due to budget cost increases (see Figure 2A) while GHG decreases due to higher energy generation from the waste system 
(more waste in incinerated). Maximum GHG savings were obtained by the case "min EC".

Generally, reducing externality costs will typically decrease GHG emissions. However, this is not always the case. For example, externality costs can be reduced by switching from plastic recycling to combustion (because non-GHG emissions, such as $\mathrm{SO}_{2}$, are avoided with the energy generation in the WtE facility), even though GHG emissions increase due to more combustion of fossil C.
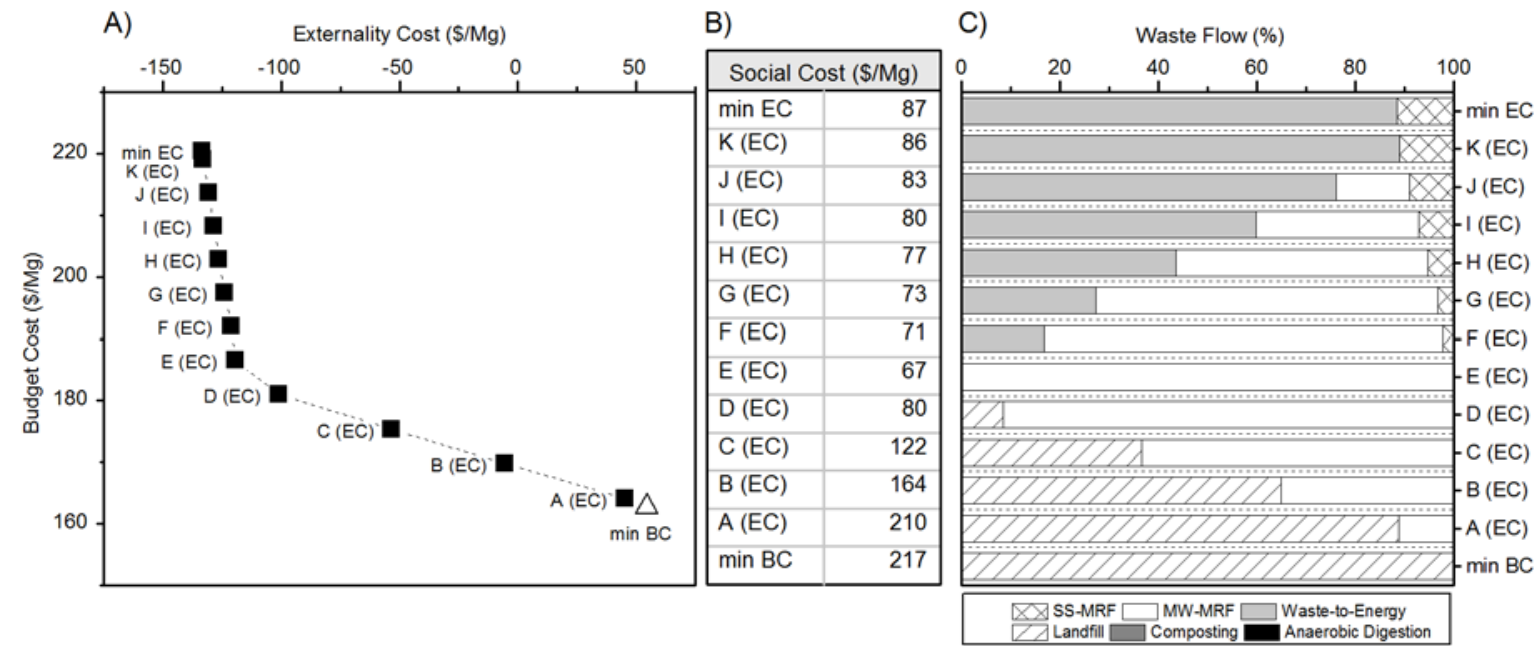

Figure 2 Optimization results using the baseline assumptions regarding waste and electricity mix composition (Tables S2 and S7). Each solution is represented by: A) a point (externality cost per Mg on the $x$-axis and budget cost per $M g$ on the $y$-axis), B) its social costs, and $C$ ) a stacked bar representing the waste flows of each solution. In A, the solutions obtained when minimizing externality costs are represented by black squares and budget costs by a white triangle. Subgraph $\mathrm{C}$ includes the first destination after collection; details on the secondary destinations are provided in Table S10.

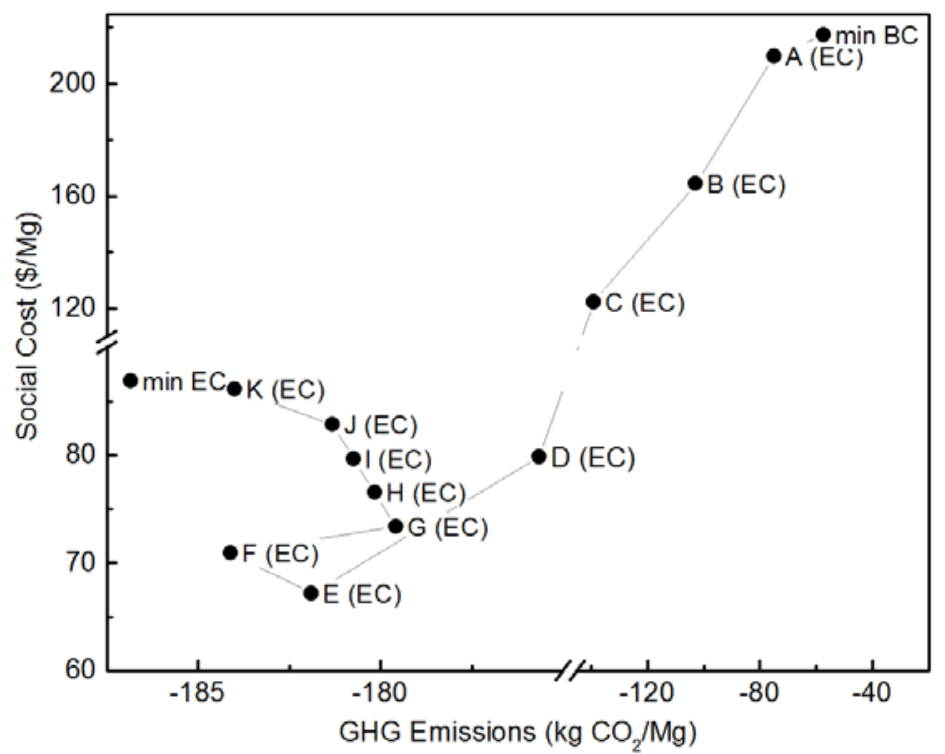

Figure 3 Optimization results shown as social costs (\$ per Mg) versus GHG emissions (kg CO2 per Mg). The letters refer to the cases shown in Figure 2. The waste flows associated with each case are summarized in Table S10. 


\section{Sensitivity Analyses}

\section{Electricity Generation Fuel Mix}

Figure 4 shows the results of the optimization (externality and budget costs of each case) when using coal and wind as alternatives to the baseline electricity mix and Table S12 shows the waste flows associated with each case.

With coal as the electricity offset, the suggested strategies were the same as for the baseline assumption (national mix). However, each strategy had lower externality costs because the energy generated in the SWM system resulted in an electricity offset with higher externality costs (\$0.54 per kWh with coal compared to $\$ 0.32$ per $\mathrm{kWh}$ with the baseline mix). As such, when the SWM is a net electricity generator, a unit of budget cost spent on the waste system generates larger environmental benefits than with a cleaner electricity mix. In contrast, wind had lower externality costs associated with the electricity offset ( $\$ 0.01$ per $\mathrm{kWh}$ ) than the baseline electricity offset. As such, SWM cases in which wind was used for electricity generation had higher externality costs than in the baseline electricity mix. The suggested waste flows with wind (Table S12) relied more on composting and less on WtE than with the baseline electricity mix because the energy substitution was less environmentally beneficial. In addition, the electricity consumed in the waste facilities, such as composting, did not have large associated externality costs. 


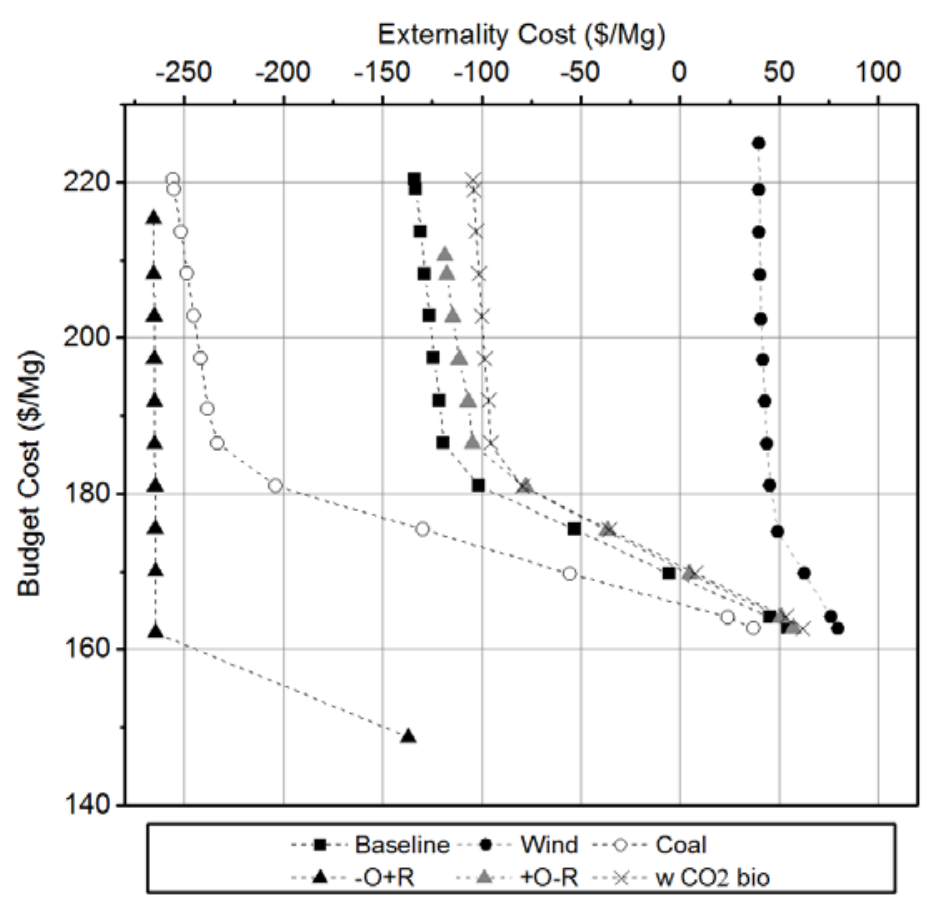

Figure 4 Budget and externality costs per Mg of waste with the baseline electricity fuel mix and waste composition (as shown in Figure 2), with wind as the electricity offset ('Wind'), with coal as an electricity offset ('Coal'), with a waste composition with lower organic content and higher content of recyclables than the baseline ('-O+R'), a waste composition with higher organic content and lower content of recyclables than the baseline ('+O-R'), and an accounting price for the biogenic CO2 equal to the fossil $\mathrm{CO} 2$ ('w CO2 bio'). The waste flows associated with these results are summarized in Tables S10, S11, S12, and S13, respectively.

\section{Waste composition}

The recyclable content in the waste was critical for the results (Figure 4). For waste composition with higher organic content and lower recyclable content than the baseline composition (+O-R), the case “min BC” again mainly relied on landfilling. However, moving towards minimal externality costs resulted in a technological shift towards WtE without including an MW-MRF, except for the case “A (+O-R)” in which the budget constraint did not allow the construction of a minimal capacity WtE, (Table S13). The associated savings in externality costs (as well as associated budget costs) were lower than the baseline composition (Figure 4) due to the fact that less material and energy can be recovered from the waste. On the other hand, in the cases with reduced organics and increased recyclable content $(-\mathrm{O}+\mathrm{R})$, the associated savings in externality costs were larger than the baseline composition, and these cases relied mostly on MWMRF and WtE for the residuals, except for the case "min BC" where residuals from the MW-MRF 
were landfilled (Table S13). Additional composting and SS-MRF further minimized externality costs slightly, but at the expense of a sharp increase in budget costs.

Overall, the higher the content of recyclables, the larger the externality savings are and the more MW-MRF capacity is applied. Some caution is advised regarding interpretation of the specific waste flows to individual technologies as a function of recyclable contents. The model assumes a constant cost/benefit per unit of waste throughput, but in reality high recycling rates may also mean more contamination and more expensive management. As such, the waste composition may be expected to affect the costs/benefits related to recovery of recyclables. In addition, such costs completely depend on the nature of the primary and secondary production and, as Brogaard et al. ${ }^{51}$ showed, there are large variations between processes.

\section{Biogenic $\mathrm{CO}_{2}$ assumption}

While the externality costs were affected by the assumption regarding the accounting of biogenic $\mathrm{CO}_{2}$, this did not affect the routing of waste flows in the system. When assuming identical accounting prices for both fossil and biogenic $\mathrm{CO}_{2}$, the externality costs were higher than when using the baseline assumption, because biogenic $\mathrm{CO}_{2}$ emissions from $\mathrm{WtE}$ and landfills carried an associated externality cost (Figure 4). However, the waste flows remained the same (Table S14).

\section{Environmental Coverage of the Externality Costs}

To evaluate whether the included externality costs cover the selected environmental impacts associated with optimal SWM strategies, a separate LCA was performed for two cases representing extreme treatment options obtained from the optimization model (minimal budget cost “min BC” and minimal externality cost “min EC”). This analysis allowed identification of critical pollutants for which accounting prices were not available but with important contributions to environmental impacts. Six impact categories were assessed: global warming (GW), acidification (AC), eutrophication (EU), photochemical ozone formation (POF), human toxicity (HT) and ecotoxicity (ET), using the LCIA methods IPCC (for GW) ${ }^{52}$, TRACI (for AC, EU and POF) ${ }^{53}$ and USEtox (for HT and ET).$^{54}$ Figure 5 shows the contribution of each pollutant to the LCA characterized results for the two cases: "min BC" and "min EC".

The emissions with available accounting prices represented the largest contributions to global warming, acidification and photochemical ozone formation. However, most of the impacts 
in eutrophication, human toxicity and ecotoxicity were caused by emissions without available accounting prices (“emissions w/o AP" bar), and thus not included in the externality costs. The eutrophication impact was dominated by ammonium and phosphorus emissions into water. Half of the human toxicity impact was due to emissions of different organic compounds, and the other half of the impact was caused by emissions of barium, mercury and zinc to water, and zinc to air. The ecotoxicity impact was mainly related to heavy metals releases, namely emissions of antimony and copper into the air and emissions of barium, chromate, mercury, silver and zinc to water (see Table S15). This indicates that efforts should be placed on expanding the range of available accounting prices with particular focus on these pollutants.

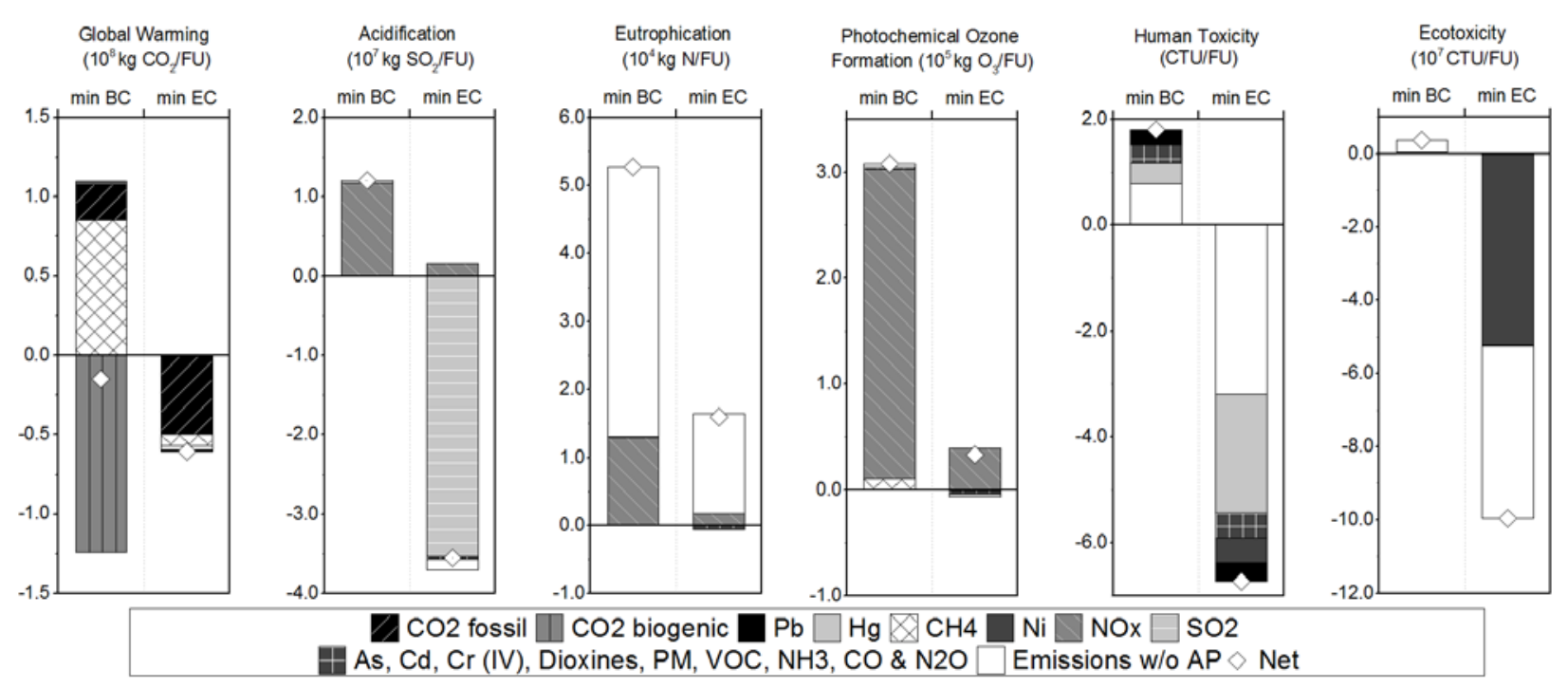

Figure 5 Substance contributions and net impacts for the "min BC" and "min EC" cases in characterized impacts using the baseline assumptions for energy and waste composition. Carbon storage in landfills and treated organics used on land are included in the $\mathrm{CO} 2$ biogenic contribution. The contribution of the emissions without accounting prices are included in the category 'Emissions w/o AP.' GW=Global warming, AC = Acidification, EU=Eutrophication, POF=Photochemical Ozone Formation, HT =Human Toxicity, ET=Ecotoxicity.

\section{Implications for policy development}

Over the last few decades, several U.S. states have established ambitious waste diversion and GHG mitigation policies. ${ }^{3}$ Although these policies may fulfill the intended goals according to specific indicators (i.e., GHG emissions and landfill diversion), this study demonstrates that integrated assessments addressing trade-offs between budget and externality costs for identification of societal optimal solutions may offer different recommendations. As shown in Figure 4, the optimal solution for minimum GHG emissions (mainly involving WtE and commingled recycling through SS-MRF) had high budget costs that were not balanced by savings in externality costs. 
Consequently, it is suggested that policy development involving SWM should target social costs comprehensively rather than addressing individual indicators, such as GHG reduction targets.

In this study, the societal optimal solution relied completely on a MW-MRF in which selected recyclables were recovered, organic residues were anaerobically digested, and non-organic residues incinerated. However, future changes in energy provision and waste composition may affect the optimal solutions. Future electricity offsets are likely to be less fossil-intensive, thereby making externality savings less likely to compensate for increased budget costs. This may shift the societal optimal solutions towards minimal budget costs. Future changes in waste composition may involve lower quantities of recyclables ${ }^{4,55}$ (e.g., generation of paper waste is decreasing), which may decrease the environmental benefits (externality savings) from recycling and at the same time lead to more expensive recovery (higher budget costs). Likewise, this may shift the societal optimal solutions towards minimal budget costs. Consequently, future changes in framework conditions may affect the technology needs within SWM. Combined assessment of budget and externality costs may therefore offer useful guidance both for SWM policy development and the associated technology improvements.

S-LCC is inherently affected by the coverage and robustness of the included emissions. Most externality costs were caused by $\mathrm{SO}_{2}, \mathrm{NO}_{\mathrm{x}}, \mathrm{PM}_{2.5}, \mathrm{CH}_{4}$, fossil $\mathrm{CO}_{2}$ and $\mathrm{NH}_{3}$ emissions, while remaining pollutants with available accounting prices had minor contributions. It is recognized, however, that the contribution of each emission depends on the waste processes/technologies used as well as the energy system. The processes in this model represent current and average waste management activities in an average US county of 500,000 people as well as current national electricity mixes, but other emissions and damages could be important in other waste and energy systems. Considerable uncertainties are associated with the magnitude of externality costs and the large variaitons within estimates. In addition, accounting price data have not been published for a wide range of pollutants and externalities such as the households willingness-to-pay for time and space associated with source-segregation. It is also recognized that accounting prices represent a limited range of damages (e.g., effects on human health). These limitations imply that S-LCC should only be used as a tool for comparative assessments between possible alternative waste management strategies, since similar uncertainties apply to all the technologies modeled. Model results are only indicators of damage costs and should not currently be used to estimate definitive damage costs of individual strategies. To further expand the use of S-LCC to overcome the above- 
mentioned challenges in policy making, current externality cost estimates have to be 1) improved for existing accounting prices beyond selected damage costs (e.g., $\mathrm{SO}_{2}, \mathrm{CO}_{2}, \mathrm{NO}_{\mathrm{x}}, \mathrm{CH}_{4}$, and metals), 2) extended with accounting prices for missing but critical pollutants, and 3) evaluated with respect to the importance of currently non-quantified externalities (e.g., time and space used by households).

\section{ASSOCIATED CONTENT}

\section{Supporting Information}

The Supporting Information is available free of charge on the ACS Publication website. A summary of accounting prices (used in this study and found in the literature) is provided as well as information regarding the waste composition, waste generation, energy mix, facility capacities, and treatment costs related to the case study. Further, extended results of the study are provided.

\section{AUTHOR INFORMATION}

\section{Corresponding author}

*Adress: Carrer Sant Joan 39, 08800 Vilanova i la Geltrú (Barcelona), Spain; Telephone: (+0034) 938935 104; E-mail: vmartinezs@ent.cat

\section{Notes}

The authors declare no competing financial interest.

\section{ACKNOWLEDGEMENTS}

Authors thank Lisbet Brusendorff from the Technical University of Denmark (DTU) for her work on the graphical abstract. This research was supported financially by the Danish Research Council through the IRMAR project. J. W. Levis was supported by the U.S. National Science Foundation (CBET-1437498).

\section{References}

(1) Martinez-Sanchez, V.; Kromann, M. A.; Astrup, T. F. Life cycle costing of waste management systems: Overview, calculation principles and case studies. Waste Manag. 2015, 36, 343-355.

(2) Bernstad Saraiva Schott, A.; Andersson, T. Food waste minimization from a life-cycle 
perspective. J. Environ. Manage. 2014, 147, 219-226.

(3) Levis, J. W.; Barlaz, M. A.; Decarolis, J. F.; Ranjithan, S. R. Systematic exploration of efficient strategies to manage solid waste in U.S. municipalities: perspectives from the solid waste optimization life-cycle framework (SWOLF). Environ. Sci. Technol. 2014, 48 (7), 3625-3631.

(4) Levis, J. W.; Barlaz, M. A.; DeCarolis, J. F.; Ranjithan, S. R. A generalized multistage optimization modeling framework for life cycle assessment-based integrated solid waste management. Environ. Model. Softw. 2013, 50, 51-65.

(5) Levis, J. W.; Barlaz, M. A. What is the most environmentally beneficial way to treat commercial food waste? Environ. Sci. Technol. 2011, 45 (17), 7438-7444.

(6) Wang, S.; Huang, G. H.; Yang, B. T. An interval-valued fuzzy-stochastic programming approach and its application to municipal solid waste management. Environ. Model. Softw. 2012, 29 (1), 24-36.

(7) Söderman, M. L.; Eriksson, O.; Björklund, A.; Östblom, G.; Ekvall, T.; Finnveden, G.; Arushanyan, Y.; Sundqvist, J.-O. Integrated Economic and Environmental Assessment of Waste Policy Instruments. Sustainability 2016, 8 (5), 411.

(8) Costi, P.; Minciardi, R.; Robba, M.; Rovatti, M.; Sacile, R. An environmentally sustainable decision model for urban solid waste management. Waste Manag. 2004, 24 (3), 277-295.

(9) Hirte, G.; Tscharaktschiew, S. Optimal Fuel Taxes and Heterogeneity of Cities. Rev. Reg. Res. 2015, 35 (2), 173-209.

(10) Pretty, J. N.; Brett, C.; Gee, D.; Hine, R. E.; Mason, C. F.; Morison, J. I. L.; Raven, H.; Rayment, M. D.; van der Bijl, G. An assessment of the total external costs of UK agriculture. Agric. Syst. 2000, 65 (2), 113-136.

(11) Ninth edition of eGRID with year 2010 data (Version 1.0); U.S. EPA, Washington, DC, 2014 http://www.epa.gov/cleanenergy/energy-resources/egrid/.

(12) United State Environmental Protection Agency. Municipal Solid Waste in The United States: 2000 Facts and Figures; 2000.

(13) CPLEX Optimizer Website; http://www01.ibm.com/software/commerce/optimization/cplex-optimizer/index.html.

(14) GLPK (GNU Linear Programming Kit) Website; http://www.gnu.org/software/glpk/.

(15) Nordic Council of Ministers. Nordic guideline for cost-benefit analysis in waste management.; 2007.

(16) Krewitt, W.; Friedrich, R.; Heck, T.; Mayerhofer, P. Assessment of environmental and health benefits from the implementation of the UN-ECE protocols on long range transboundary air pollution. J. Hazard. Mater. 1998, 61 (1-3), 239-247.

(17) Eshet, T.; Baron, M. G.; Shechter, M. Exploring Benefit Transfer: Disamenities of Waste Transfer Stations. Environ. Resour. Econ. 2006, 37 (3), 521-547.

(18) Eshet, T.; Ayalon, O.; Shechter, M. Valuation of externalities of selected waste management alternatives: A comparative review and analysis. Resour. Conserv. Recycl. 2006, 46 (4), 335-364. 
(19) Eshet, T.; Ayalon, O.; Shechter, M. A critical review of economic valuation studies of externalities from incineration and landfilling. Waste Manag. Reseach 2005, 23 (6), 487504.

(20) Rabl, A.; Spadaro, J. V.; Zoughaib, A. Environmental impacts and costs of solid waste: a comparison of landfill and incineration. Waste Manag. Res. 2008, 26 (2), 147-162.

(21) Rabl, A.; Benoist, A.; Dron, D.; Peuportier, B.; Spadaro, J. V.; Zoughaib, A. How to account for $\mathrm{CO} 2$ emissions from biomass in an LCA. Int. J. Life Cycle Assess. 2007, 12 (5), 281281.

(22) Dijkgraaf, E.; Vollebergh, H. R. J. Burn or bury? A social cost comparison of final waste disposal methods. Ecol. Econ. 2004, 50 (3-4), 233-247.

(23) European Commission, D. E. A Study on the Economic Valuation of Environmental Externalities from Landfill Disposal and Incineration of Waste. Final Appendix Report http://ec.europa.eu/environment/waste/studies/pdf/econ_eva_landfill_annex.pdf (accessed Jan 14, 2015).

(24) Zaks, D. P. M. Reducing negative environmental externalities rfom agricultural production: methods, models and policies, University of Wisconsin-Madison, 2010.

(25) Tegtmeier, E. M.; Duffy, M. D. External costs of agricultural production in the united states. Int. Jounal Agric. Sustain. 2004, 2 (1), 1-20.

(26) Granderson, G.; Prior, D. Environmental Externalities and Regulation Constrained Cost Productivity Growth in the U.S. Electric Utility Industry. J. Product. Anal. 2012, 39 (3), 243-257.

(27) Bernow, S. Full-cost dispatch: Incorporating environmental externalities in electric system operation. Electr. J. 1991, 4 (2), 20-33.

(28) Roth, I. Incorporating externalities into a full cost approach to electric power generation lifecycle costing. Energy 2004, 29 (12-15), 2125-2144.

(29) Delucchi, M. Environmental externalities of motor-vehicle use in the US. J. Transp. Econ. POLICY 2000, 34, 135-168.

(30) ExternE. ExternE - External Cost of Energy http://www.externe.info/externe_d7/.

(31) Grosse, S. Economic gains resulting from the reduction in children's exposure to lead in the United States. Environ. Health Perspect. 2002, 110 (6), 563-569.

(32) US EPA. Social Cost of Carbon. Accessed from http://www.epa.gov/climatechange/EPAactivities/economics/scc.html; 2015.

(33) Tol, R. S. J. The marginal damage costs of carbon dioxide emissions: an assessment of the uncertainties. Energy Policy 2005, 33 (16), 2064-2074.

(34) RDC Environment. Evaluation of costs and benefits for the achievement of reuse and recycling targets for the different packaging materials in the frame of the packaging and packaging waste directive 94/62/EC; 2001.

(35) IPCC. Fourth Assessment Report; 2007.

(36) EUNOMIA. Economic analysis of options for managing biodegradable municpal waste. Accessed from 
http://ec.europa.eu/environment//waste/compost/pdf/econanalysis_finalreport.pdf; 2002.

(37) Rabl, A.; Benoist, A.; Dron, D.; Peuportier, B.; Spadaro, J. V.; Zoughaib, A. How to account for CO2 emissions from biomass in an LCA. Int. J. Life Cycle Assess. 2007, 12 (5), 281281.

(38) Muller, N. Z.; Mendelsohn, R.; Nordhaus, W. Environmental Accounting for Pollution in the United States Economy. Am. Econ. Rev. 2011, 101 (5), 1649-1675.

(39) Mauzeral, D. L.; Sultan, B.; Kim, N.; Bradford, D. F. Charging NOx Emitters for Health Damages: An Exploratory Analysis; CEPS Working Paper No. 103; 2004.

(40) Fann, N.; Baker, K. R.; Fulcher, C. M. Characterizing the PM2.5-related health benefits of emission reductions for 17 industrial, area and mobile emission sectors across the U.S. Environ. Int. 2012, 49, 141-151.

(41) Muller, N. Z.; Mendelsohn, R. Efficient Pollution Regulation: Getting the Prices Right. Am. Econ. Rev. 2009, 99 (5), 1714-1739.

(42) Muller, N. Z.; Mendelsohn, R. Measuring the damages of air pollution in the United States. J. Environ. Econ. Manage. 2007, 54 (1), 1-14.

(43) Fann, N.; Fulcher, C. M.; Hubbell, B. J. The influence of location, source, and emission type in estimates of the human health benefits of reducing a ton of air pollution. Air Qual. Atmos. Health 2009, 2 (3), 169-176.

(44) Matthews, H. S.; Lave, L. B. Applications of Environmental Valuation for Determining Externality Costs †. Environ. Sci. Technol. 2000, 34 (8), 1390-1395.

(45) Rice, G.; Hammitt, J. K. Economic Valuation of Human Health Benefits of Controlling Mercury Emissions from U.S. Coal-Fired Power Plants; 2005.

(46) Trasande, L.; Landrigan, P. J.; Schechter, C. Public Health and Economic Consequences of Methyl Mercury Toxicity to the Developing Brain. Environ. Health Perspect. 2005, 113 (5), 590-596.

(47) Spadaro, J. V; Rabl, A. Global health impacts and costs due to mercury emissions. Risk Anal. 2008, 28 (3), 603-613.

(48) Pizzol, M. External costs of atmospheric Pb emissions: valuation of neurotoxic impacts due to inhalation. Environ. Heal. a Glob. Access Sci. Source 2010, 9 (9).

(49) Xu, L.; Chen, J.; Niu, Z.; Yin, L.; Chen, Y. Characterization of mercury in atmospheric particulate matter in the southeast coastal cities of China. Atmos. Pollut. Res. 2013, 4 (4), 454-461.

(50) European Commission, D. E. A Study on the Economic Valuation of Environmental Externalities from Landfill Disposal and Incineration of Waste. 2000.

(51) Brogaard, L. K.; Damgaard, A.; Jensen, M. B.; Barlaz, M.; Christensen, T. H. Evaluation of life cycle inventory data for recycling systems. Resour. Conserv. Recycl. 2014, 87, 30-45.

(52) IPCC - Intergovernmental Panel on Climate Change. Fifth Assessment Report. http://www.ipcc.ch/ (accessed Apr 24, 2015).

(53) Bare, J. C. TRACI: The tool for the reduction and assessment of chemical and other environmental impacts. J. Ind. Ecol. 2002, 6 (3-4), 49-78. 
(54) Rosenbaum, R. K.; Bachmann, T. M.; Gold, L. S.; Huijbregts, M. A. J.; Jolliet, O.; Juraske, R.; Koehler, A.; Larsen, H. F.; MacLeod, M.; Margni, M.; et al. USEtox-the UNEPSETAC toxicity model: recommended characterisation factors for human toxicity and freshwater ecotoxicity in life cycle impact assessment. Int. J. Life Cycle Assess. 2008, 13 (7), 532-546.

(55) US, E. P. A. Full Cost Accounting for Municipal Solid Waste Management: A Handbook; 2006. 